\title{
Foreign Language Learning Pedagogy: Learner Centredness vis-à-vis Linguistic Competence - Action and Reaction
}

\author{
Jamel Chaaraoui \\ English Language Institute, The University of Jeddah, Jeddah, Kingdom of Saudi Arabia
}

Email address:

jamelchaaraoui@yahoo.com

\section{To cite this article:}

Jamel Chaaraoui. Foreign Language Learning Pedagogy: Learner Centredness vis-à-vis Linguistic Competence - Action and Reaction. International Journal of Language and Linguistics. Vol. 5, No. 6, 2017, pp. 187-200. doi: 10.11648/j.ij11.20170506.14

Received: August 16, 2017; Accepted: September 11, 2017; Published: December 20, 2017

\begin{abstract}
It is well-expected that in the cause-and-effect relationship, authentic formal language learning four hours weekly for six years and 18 hours a week for nearly one year is very likely to produce learners with language proficiency enough to conduct simple conversations about basic daily life issues. Through measuring the global grammar accuracy in the oral language of foundation students at the English Institute at King Abdul Aziz University, the present study aimed at examining how far the learner is the centre of the learning operation so that it can correspondingly yield a considerable amount of EFL linguistic proficiency. The results, however, show that even the most basic grammar norms of the target language (TL) have not yet been acquired, and the learners' TL grammar is so inaccurate that it severely affects the oral output intelligibility. That highly inaccurate TL grammar calls for the reestablishment of the learning aims, approaches, and tools in serious quest for more learner-centredness in the learning task so that those severe linguistic gaps can be abridged and more authentic TL acquisition is achieved.
\end{abstract}

Keywords: Grammar Global Inaccuracy, Learner-Centredness, Authentic TL Acquisition

\section{Introduction}

Learning a second language (SL) is a process of gradual acquisition of a new language system that depends on the learner's needs, length of exposure, and amount of practice. Accordingly, the more SL learners acquire the second language (L2), the higher level of proficiency they will achieve and the lower their dependence on the L1 will become. So, as the awareness of the L2 grammatical norms grows, the more the explicit language knowledge will turn into implicit (Van Patten 1990), and the more spontaneity and automaticity of SL processing will crop up. However, language acquisition does not take place when the language learner is not at the proper centre of that course of action. In such a case, L2 learning will continue to be in its primary stages, and the learner will keep full dependence on L1 in interpreting and producing the L2 grammar (Cummins 1979).

In a bottom-up approach, the present study aims at investigating the amount of learner-centredness in the FL learning process that can be reflected through the amount of grammar global accuracy detected in the FL learners' oral output analysed. The aim is to examine how learnercentredness translates the learner needs for useful ad motivating language materials, tasks, and activities into more TL acquisition and more accurate TL production.

At an early stage of SL learning, language errors are supposed to be interlingual, where the L1 norms still have a strong influence in the production of L2 grammatical system. However, as the SL learning advances, those errors are expected to be restricted to the L2, showing development in L2 knowledge, and the L2 grammar production more L2 norm-bound. The quality of the language output mirrors that the learner is advancing as long he/she the focus of the teacher and the curriculum given that his/her learning needs have been worked on and satisfied since the first day of TL learning.

In the intact SL learning process, the language teacher is required to show awareness of the students' needs and to be 
friendly, sociable, cooperative, creative in choosing motivating tasks, and an artist in correcting students' errors. Based on those factors; the student's needs, characters, interests, hobbies, talents, motivating topics, and comfort would be the basis of the teacher's selection and choice of the teaching materials, topics, activities, and the type of language practice and its frequency. Creative teachers who are aware of their demands are very likely to make the students motivated, cooperative, productive, and their learning outcome would reflect gradual improvement with time.

\subsection{Grammar Definition}

The term grammar or the system of a language as investigated in this study subsumes both the structure of words and the syntactic relationships between them, adopting the definition of grammar as "the whole system and structure of a language usually consisting of morphology and syntax (including inflections)" Oxforddictionaries (17 April 2017). In a restricted sense, the term refers only to the study of sentence and word structure (syntax and morphology), excluding vocabulary and pronunciation. (Encyclopedia Britannica).

\subsection{Grammar in Communication}

Grammar is an important language feature upon which the meaning and interpretation of oral messages are based. It is well-established in the literature that grammar knowledge is highly correlated with the level of accuracy in communication. According to Widdowson (1990), attention is given to communicative economy and meaning during communication, which language structure establishes together with accuracy and elaborateness. As for Cummins (1979), grammar proficiency threshold is the proper reflection of the whole language threshold level. When the grammar accuracy is low, the learner's faulty inferences are based on their L1 system, but when grammar is more accurate, potential errors would be of intralingual types. Homburg (1984) contends that errors are also better categorised in terms of their communicative effect. Semantic decoding is naturally based on syntactic processing so that comprehension takes place (Nation and Newton 2009).

Obviously, regardless of the sort of the language error, grammar accuracy prevents both communication breakdown and speech act misinterpretation. Different topics may encourage different grammatical forms. However, as the topics were chosen by the learners themselves in the present study, they are not a source of pressure or specific forms elicitation. Therefore, the ability to compare accuracy across topics would be so global. Also, with the learners sharing the same academic level and language background, even specific language forms would be dealt with homogenously.

\subsection{How to Measure Grammar Accuracy}

The present study is cross-sectional, investigating the level of grammar accuracy in the language of the Saudi EFL foundation students after nearly 7 years of exposure to
English as a foreign language; 3 intermediate, 3 secondary, and almost 1 at university. The aim was to take a snapshot of the learners' amount of grammar accuracy in English, especially the types of L2 errors; interlingual or intralingual, lexical or morphological grammar. Every grammar error recorded is counted to shape up the TL profile of the learners under study. The videotaped oral presentation test was prepared in advance by the students who had been free to choose the topics they would have to present in the oral test. The oral output was transcribed, and segmented into ASUnits. Also, the error analysis research steps are followed: collecting samples of learner language in numbers and frequencies in a quantitative exploration of the learners' grammar competence, identifying the errors, describing them - local and/or global, explaining them, and finally evaluating them (Corder 1981).

The study aims at making a quantitative analysis of grammar global accuracy in a more straightforward than longitudinal one to detect the development of grammar forms as some forms develop rather curvilinearly and thus are too misleading to reflect the true interlanguage grammar competence over time (Ortega 2003). The oral presentation test was meant to be a form of clinical elicitation (Corder 1981) which aims at getting the informant to produce data of any sort in two speech modes preplanned closed task, the monologue, and online planned open task, the dialogue.

The precise discourse features measured in the present study are made up of both sentence and word structure; nouns, determiners, pronouns, verbs, adjectives, adverbs, prepositions, and conjunctions are discreetly measured (Ellis and Barkhuizen (2005) over a length of oral language output. As a Second Language Acquisition (SLA) research, the present study adopts the objective measures based on Ellis and Wolfe-Quintero Operationalisation of Accuracy (Ellis, (2003: 117); Wolfe-Quintero et al. (1998: 137-144)), error density, types of errors, mean number of errors per 100 words (Kuiken \& Vedder, 2007), and errors per AS-Units (Lambert $\&$ Engler, 2007). That would give account of how the learners' language abide by the TL norms. In fact, 'the purpose of accuracy measures is precisely the comparison with target-like use in every oral aspect' (Ellis and Barkhuizen 2005: 36).

The errors are categorised into omission, substitution, addition, and permutation (Corder 1973) in order to obtain precise accounts of the different aspects of spoken language (Ellis \& Barkhuizen, 2005). Those discreet measures of both lexical and morphological grammar were first introduced by Ishikawa (1995) to reveal how much grammar the EFL learner under study has acquired.

The results would certainly reflect the job of the three main partners: 1) the amount of the learners' awareness of L2 norms which is built and piled over a long time of proper classroom learning and language practice of 2) a motivated learner who is the centre of EFL learning process and 3) a creative teacher who is expected to be a monitor, a facilitator, a controller, a director, etc. depending on his/her well-chosen types of tasks to meet the needs of his/her students. In this 
case, the more grammatically accurate the oral output of the learner is, the more that learner is given focus, and the more the learning process is based on his needs.

\subsection{Why Measure Grammar Accuracy}

The bigger the degree of deviancy from the L2 norm, the poorer the quality of the L2 (Wolfe-Quintero et al. 1998). Accuracy can be attained after proper acquisition and enough practice of L2. So, more L2 acquisition implies fewer grammar errors and less L1 transfer (Skehan \& Foster 1999). Practice is based on the choice of a variety of activities where the leaner is an active participant. Language activities and practice depend on a large scale on the established teacherstudent (T-S) relationship. They are chosen on the basis of the T-S partnership where friendliness and mutual understanding prevails. Language learning context is so dynamic that teacher's knowledge of the students is so vital it ensures learning, practice, and acquisition easily, fast, and comfortably.

\section{Literature Review}

The acquisition of the TL grammatical system is of a great value because an inadequate knowledge of grammar could severely restrict the scope of linguistic creativity and limit the capacity for communication (Wilkins (1976: 66). In other words, grammar rules are there to enable us to properly "mean" what we say, and without grammar knowledge, it is impossible to communicate beyond a very rudimentary level. Formal instruction of grammar, in Ellis's (1990) terms refers to "the attempt to teach some specific features of the L2 code - usually grammatical features - in one way or another" to equip language learners with necessary language framework. However, in the foreign academic context, where the EFL learner's rare exposure and minimum practice of the TL makes of the language framework explicit, decontextualized, and easily forgotten. That usually leads to more influence of L1 grammatical norms through which L2 is acquired and produced.

On the one hand, Terrell (1991) presents evidence that direct grammar instruction did not guarantee to L2 learners the ability to freely engage in a spontaneous conversation. On the other hand, she demonstrates that grammatical knowledge plays a significant role in the learners' overall language proficiency. In the same line, pro-grammarians such as Ebsworth and Schweer (1997) strongly believe that grammar competence helps the accuracy and speed of L2 learning and acquisition. Her study reveals the strong relationship that grammar has with all language skills (Terrell, p. 56).

The three advantages of grammar instruction are the following: 1) it accelerates learning, 2) affects the acquisition process in the long-term accuracy (Ruiz-Funes, 1999, p. 521), 3 ) resulting in more communicative competence. In the same respect, Salomone (1992) reports that an immersion program in the United States started adopting explicit teaching of grammar after verifying the students' inaccurate speech.

Scott \& Tucker (1974) studied errors Arabic-speaking students made in their speech and writing and found that verbs, prepositions, and articles were major sources of errors. Also, they found in that a great number of errors were caused by the first language interference either through overgeneralization, analogy, incomplete application of rules, or false hypothesis based on limited knowledge of the target language. El-Sayed (1982) investigated the frequent syntactic errors by Saudi and his findings supported the claim that mother tongue interference was the prime cause of EFL student errors. Abisamra (2003) points out that Arab EFL learners commit interlingual errors more than intralingual ones. Similarly, Hachem (1996) found that the majority of errors, especially the word structure, are made under the effect of L1 transfer. Added to that, Abisamara (2003) and Tahaineh (2010) contended that most writing errors made by Arab students fall in the category of grammar and syntax and are aspects of L1 interference.

\subsection{Teaching Grammar}

Grammar is not an end in itself, it is but a tool for communicative function. It is like the engine that enables the motor to move when the driver intends, or like spices that give a certain flavour to food. Yet, there is a lack of consensus between researchers and scholars on grammar teaching; whether should it be form-focused or communication-based. For the scholars, who are pro Natural approach (Krashen \& Terrell, 1983), grammar has no role, as it was considered a detriment to communication. Other researchers like (Ellis, 2006:102) contend that there is ample evidence to demonstrate that teaching grammar works, and that both proactive and reactive explicit form-focused instruction FFI assist acquisition.

Similarly, grammatical competence is viewed as integral to all language skills (Council of Europe, 2001:112-113). A more balanced stand is expressed by Hill and Flynn (2006:23) who suggest that, "Language structure and form should be learned in authentic contexts rather than through contrived drills in language workbooks". Researchers insist that conscious learning of grammatical rules "is a prerequisite to acquiring communicative competence" (Krashen \& Terrell, 1983, p. 16). Even a clearer standpoint expressed by Nassaji and Fotos (2011, p. 14) that "if the goal of second language learning is to develop communicative competence and to enable learners to use language accurately and fluently for communicative purposes, a focus on grammar must be incorporated into L2 communicative instruction". Certainly, it is difficult to concentrate on communication only and turn a blind eye to the fact that without grammar competence, communication breaks down. More importantly, grammar learning has to be contextualized, both explicit and implicit depending on the activity assigned, and within a learnercentred approach that represents an endless quest to meet up the learner's needs.

\subsection{Learner-Centredness and Grammar Teaching}

When the student is the focus of the learning task, there 
should be tailor-made and richly varied activities (Javid 2011) to meet the needs of the learners. Both inductive or deductive approaches are needed based on the type of task and grammar rule(s). Creativity, variation, and suitability are key qualities of the activities that address the learner's needs and also reflect the awareness, artistic vision, and professionalism of the teacher who is able to provide appealing and motivating activities.

As the type of task or activity is attuned to the student needs, the teacher will assume various roles; a facilitator, a monitor, a guide, an advisor, etc. while the learner is likely to be motivated and participating actively and productively in the learning process. The richness and stimulation of language practice encourage the learner to question, argue, think, and be a recognizable learning partner. Appealing topics and tasks make learners more attentive. They even become more appealing when they refer to leaners' interests, hobbies, and characters. It is then that the learner can be encouraged express himself or herself more expressively.

Learner-centred approach considers learner errors as major part of the learning process. It becomes more important when it is repeated in different tasks; to be first corrected and then rechecked for acquiring the correct form(s). The error correction is a strong indication of learner-centredness. It helps learners to change their earlier knowledge could be wrong and follow up the language learning process on a solid ground. In this respect, $\mathrm{Li}$ (2012:170) suggests that the responsibility of error correction can be assumed by the student, and that strengthens the teacher-student cooperation, mutual understanding and cooperation. From another perspective, Hill and Flynn (2006:32) pint out that "the best way to provide corrective feedback when grammar or pronunciation errors are made is simply to model the correct English without overtly calling attention to the error". That would also be a successful strategy to gain the attention of the proficient who also need to say that they are there to show language proficiency. They most of the time prefer their errors to be corrected indirectly, without referring to their work or their names. Interestingly, Gass (2003) assumes that language learning depends upon three key factors: 1) a high quality exposure to a large quantity of target language, 2) abundant opportunities to engage in the production of the $\mathrm{TL}$ with 3) the use of linguistic resources in real-time communication. It has been pointed out that such a type of exposure of the TL in context can take the form of a positive evidence; exemplars of the TL features that are abundant enough to draw the learner's attention through multiple instances (Mangubhai, 2006).

\section{Theoretical Framework}

The learner centredness in the process of language learning is clearly reflected in the diversification and abundance of the teaching materials that have to be creative, suitable, and motivating enough to motivate the learner and attract him/her to work more comfortably and productively, and to make them more aware of the norms that govern the TL grammatical system. The abundant practice of well-tailored TL structure is determined by the learner's highly accurate linguistic output.

To investigate that issue, the present study plans to focus on the following concepts: The amount of grammar global accuracy, as the code to meaningful communication, clearly reflects the quantity and quality of the linguistic input learned in class and derived from the firm belief that language learning is fully based on the learner as the centre and the sole target of that process. The aim is to detect how the grammar accuracy in the language of the learner reveal is closely related to the learner-centredness theory. The research questions are:

How accurate is the global grammar in oral output of the EFL learner under study?

If not accurate, are the errors basically interlingual or intralingual, and how do the types of errors reflect the amount of exposure and the fact that the learner is not the centre of the learning process despite the long period of exposure?

\section{Rationale}

The present study aimed at investigating the relationship between the amount of L2 grammar accuracy in the language of the EFL learner after nearly 7 years of exposure and the learner-centred second language learning approach in that academic context. The more accurate the learners' linguistic output is, the more those learners have been taken care of in terms of their learning needs, their preferences, their TL grammar weaknesses, and their motivating activities and topics. This bottom-up study explores the results that reveals a lot about the causes.

\section{Method}

As shown in the chart below, there are five accuracy parameters employed based on the accuracy operationalisation of Ellis (2003) and Wolfe-Quintero et al. (1998).

Table 1. The Grammar and Syntactic Variables Measured in the Monologue and Dialogue.

\begin{tabular}{ll}
\hline MONOLOGUE & DIALOGUE \\
\hline Error density & Error density \\
Error free AS-Units & Error free AS-Units \\
Frequency of errors per AS-unit & Frequency of errors per AS-unit \\
Mean number of Error per 100 & Mean number of Error per 100 \\
words & words \\
Most common error procedure & Most common error procedure \\
Most common error type & Most common error type \\
\hline
\end{tabular}

\subsection{Participants}

In order to investigate the level of grammar accuracy in the oral language production of EFL foundation learners, a group of 50 male foundation students were randomly selected; 25 doing English language course for science-oriented and 25 doing English language course for arts-oriented students. 
They are all foundation students at King Abdul Aziz University. All the participants were males with a mean age of 20 years. Also, all the learners had almost seven years of exposure to English as a foreign language in Saudi Arabia, 3 years in the intermediate school, 3 years in secondary school, and almost a complete year at university.

\subsection{Materials}

The materials used in this study are videotaped oral presentation test conducted by an English native-like teacher with his 50 Saudi EFL foundation students. The speaking task consists of two modes of speech: a monologue prepared by the students in advance and a dialogue which consists of a few questions to elaborate for the topic exposed in the monologue. The data collection went through 4 phases: (1) transcribing the videotaped oral presentations, (2) segmenting the transcripts into AS-Units, (3) analysing the grammar global errors and categorizing those errors into numbers, types, procedures (omission, addition, substitution, and permutation (Corder, 1973).

\subsection{Procedures}

To achieve the aims of the present study and to verify hypotheses, the videotaped oral presentations were transcribed and segmented, and the global grammar accuracy measures - category and type of grammar, both lexical and morphological, were counted in number and frequency in both modes of speech.

\section{Results and Discussion}

This part includes the results obtained after data collection and data analysis.

\subsection{Results}

The results will account for the errors recorded in terms of density, categories, types, and frequency. In this respect, it is important to point out that the language is grammatically inaccurate. More specifically, the level of grammatical accuracy is uneven between the two modes of speech. More accurate grammar in the pre-planned monologue and with more substitution error categories whereas in the dialogue, the online-planned dialogue is less accurate and with the more dominance of omission errors category. Last but not least, the sole majority of errors are interlingual.

\subsubsection{Error Density}

The density of errors in the monologue is sharply different from the one in the dialogue.
In the monologue, there is a mean average of 169.20 words produced, and that number is high enough to express any idea or describe any scene, event, or a point of view. It reflects a considerable language knowledge, command and proficiency on the part of the speaker whose language repertoire seems to be rich enough to allow for selfexpression and for the choice of a variety of topics. Similarly, the density of language production is reinforced by the big number of AS-Units produced in the monologue - 17.42 ASUnits with 9.5 words per unit. In terms of language quality, the mean number of sentences is 10.68 . That number is surprising as the mean number of words can hold more sentences.

The AS-Unit is syntactically-based and flexible enough to include even single words (Ellis 2003). Despite that, there are as many as 9.5 words per AS-Unit higher than the ideal number which is 7 to 9 words per English sentences in spoken language which is considered less complex than the written one. However, the speakers' language command is better identified after detecting the density and types of grammar errors made in that big number of words produced. Accuracy wise, the mean number of grammar errors is 11.89 errors per 100 words. That sizable amount of errors drives the oral output produced not to be very accurate grammatically $(\mathrm{C})$ given the 10-day period of time provided to the students to prepare their oral presentation topics.

Clearly, the considerably dense language produced in the monologue is highly inaccurate as described by Ellis (2003) who defined accuracy as "the extent to which the language produced in performing a task conforms to native speaker norms" (p. 339). That is, the learners' type of interlanguage in this academic context seems to be an accumulation of unrefined TL knowledge over the years. That high level of error density reflects the fact that the learner has not formally acquired much of the TL structural norms due to the lack of enough exposure and practice required when he is the centre of the TL teaching efforts. English is necessary only in science majors in higher education but not highly urgent for future jobs or for daily communication. Back in time, teachers of English in the intermediate and secondary schools extensively use the learners' mother tongue as the sole means of communication and language of instruction (Fareh 2010). So, the absolute majority of students learn English instrumentally; to get the pass grade. As a result, the students' type of English is made up of scrambled parts of speech clinging in the mind over the years more than a buildup of language structures developed and refined over the course of time.

Table 2. Number of Errors Made by All the Subjects both in the Monologue and the Dialogue.

\begin{tabular}{|c|c|c|c|}
\hline & ELCS & ELCA & TOTAL \\
\hline \multicolumn{4}{|l|}{ MONOLOGUE } \\
\hline Mean number of words & 254,13 & 94.43 & 169.20 \\
\hline Mean number of errors in grammar & 28.3 & 11.95 & 20.12 \\
\hline Mean Number of errors in grammar per 100 words & 11,13 & 12.65 & 11.89 \\
\hline
\end{tabular}




\begin{tabular}{llll}
\hline & ELCS & ELCA & TOTAL \\
\hline MONOLOGUE & & & \\
\hline Mean Number of Words per AS-Unit & 11.02 & 7.98 & 9.5 \\
Mean Number of AS-Units & 23,02 & 11.82 & 17.42 \\
Mean number of sentences & 13.98 & 7.38 & 10.68 \\
DIALOGUE & & \\
Mean number of words & 72.21 & 28.19 & 50.2 \\
Mean number of errors in grammar & 12.96 & 7.48 & 10.22 \\
Mean Number of errors in grammar per 100 words & 17.94 & 26.53 & 20.36 \\
Mean Number of Words per AS-Unit & 6.13 & 2.86 & 4.49 \\
Mean Number of AS-Units & 11.51 & 10.10 & 10.80 \\
Mean number of sentences & 4.34 & 0.96 & 2.65 \\
\hline
\end{tabular}

In the dialogue, the mean number of words produced is 50.2 , exactly $29.67 \%$ of the mean number of words produced in the monologue although the dialogue was meant to elaborate on the ideas and topics produced in the monologue. After the speaker gains confidence in the monologue, his performance is expected to be better and his language of more quality. On the opposite, together with the very few words produced, the mean number of AS-Units produced in the dialogue is 10.80 . That number is misleading as the number of words per ASUnit does not exceed 4.49 , less than $50 \%$ of the number of words produced per AS-Unit in the monologue. Another strong reinforcement of the poor language performance is the high mean number of errors per 100 words. It is as enormous as 20.36 errors. On the other hand, the number of sentences produced in the dialogue is just 2.65; almost all the words produced were sporadic as no syntactic body was built to arrange them.

The language performance is statistically homogenous across the two modes of speech. In the monologue, the considerable number of words produced goes hand in hand with the high number of AS-Units, the mean number of words per AS-Unit, and the average number of sentences. That good quantity of language produced in the monologue raises expectation that equal or bigger number of words will be produced in the dialogue. Accuracy wise, the number of grammar errors in that mode of speech was above average.

In the dialogue, however, the mean average of words produced is so low, and the number of words per AS-Unit which is even shockingly small. The sentences produced are also scarce while the number of grammar errors has risen meteorically. That is reminiscent of the total lack of language knowledge and language command. An explanation of the highly thin AS-Units shows that they are but short, most of the time single-word answers although the questions asked by the interlocutor were for the sake of more elaboration of the topic previously chosen and exposed by the learner. So, those answers were too short to include clauses, pauses, or cut-off points. They are many only because the interlocutor, the researcher's colleague, was trying varying the types of questions and keeping them all within the speaker's topic just to motivate the speaker to produce more language. The shortness of the answers reveal lack of enough language the in the speakers' repertoire that may enable them to express himself in spite of their familiarity of the topics. In sum, the preplanned task is incomparably more accurate and more productive than the online task where the quantity of language is meagre, and the errors are highly frequent.

\subsubsection{Error Categories}

The error categories, which are omission, addition, substitution, and permutation, serve as a mirror to reflect the balance between L1 and L2 or predominance of any of them in the learner interlanguage system translated in the linguistic norm abidance in this academic context. They also display the nature of the linguistic gaps; interlingual as is the case under study or intralingual which show a higher level of proficiency level. on the part of the language user.

As shown in the chart below, the mean number of errors is 20.12 per 169.20 words - the mean number of words produced in the monologue. More specifically, the error procedures in the monologue are ranking as follows:

1) $43.58 \%$ of the grammar errors made are substitution errors;

2) $41.77 \%$ are omission errors;

3) $9.22 \%$ are addition errors;

4) $3.17 \%$ are permutation errors.

Clearly, in the preplanned, closed task, the monologue, the speaker has time to prepare, reformulate, and edit what they intend to say and therefore be as accurate as he/she can. In such a mode of speech, the substitution is the most common error category. That is expected as the speaker has time to find the correct grammar structure to convey the message intended. So, the erroneous substitution category seems highly convenient for more expressiveness in this case.

More specifically, the substituting parts of speech and grammar structures imply awareness of the speakers about L2 grammar norms, and that entails a considerable L2 proficiency level. Low proficiency level learners do not have richness of grammar rules and a variety of alternative speech parts in their language repertoire to employ as alternatives for substitution. That raises more expectations of having a higher level of L2 competence and a better language performance in the next task, the dialogue.

However, the second most employed erroneous category in the monologue is the omission one. Although it ranked second, it is not very different in amount from the percentage of substitution. Omitting parts of speech represents lack of awareness, a strict deviance from L2 grammar system norms, and a serious break of the language grammar rules. The 
conviction of the seriousness of such error category is reinforced by the erroneous additions which ranked third with $9.22 \%$. That is, omitting or adding a grammar element represents a serious deviance to grammar norms more than substituting or permuting that element. The oral presentation task is an academic test in which the learners compete to get the best grade.

Also, the foreign language learnt in class is standard; L2 dialects and/or varieties are ruled out. So, the high percentage of erroneous omissions automatically implies lack of awareness of the L2 grammatical system and a low L2 grammar proficiency level. That also leads to two logical interpretations: the learners under study have a low English proficiency level, and the quantity and quality of language of language is prepared and frequently practised before the test. Also, the substitution errors that ranked first does not mean richness in alternative parts of speech and grammar structures in the speakers' language repertoires. Instead, those substitution errors were instances of overgeneralising L1 grammar rules.

Table 3. Error Procedures Reported in the Monologue and Dialogue of All the Subjects Dialogue.

\begin{tabular}{|c|c|c|c|}
\hline & ELCS & ELCA & TOTAL \\
\hline \multicolumn{4}{|l|}{ MONOLOGUE } \\
\hline Mean number of errors & 28.3 & 11.95 & 20.12 \\
\hline Percentage of substitution errors & $51.02 \%$ & $36.15 \%$ & $43.58 \%$ \\
\hline Percentage of omission errors & $34.34 \%$ & $49.20 \%$ & $41.77 \%$ \\
\hline Percentage of addition errors & $9.75 \%$ & $8.70 \%$ & $9.22 \%$ \\
\hline Percentage of permutation & $3.67 \%$ & $2.67 \%$ & $3.17 \%$ \\
\hline \multicolumn{4}{|l|}{ DIALOGUE } \\
\hline Percentage of substitution errors & $63.58 \%$ & $24.6 \%$ & $44.09 \%$ \\
\hline Percentage of omission errors & $43.83 \%$ & $75.94 \%$ & $59.88 \%$ \\
\hline Percentage of addition errors & $24.07 \%$ & $16.04 \%$ & $20.05 \%$ \\
\hline Percentage of permutation & $9.56 \%$ & $4.27 \%$ & $6.91 \%$ \\
\hline
\end{tabular}

In the dialogue, where language production is more spontaneous and more expressive of the speaker's interlanguage competence, the mean number of errors is 10.22 in every 50.2 words produced. As can easily be noted, the language produced in this task is extremely erroneous. More specifically, the error categories ranking has changed as follows:

1) $59.88 \%$ of the grammar errors are omission errors.

2) $44.09 \%$ are substitution errors.

3) $20.05 \%$ are addition errors.

4) $6.91 \%$ are permutation errors.

In the dialogue, the language produced is so poor syntactically and quantitatively. Similarly, the omission error category has become the most frequent. Although the learners had been given ten days to competitively prepare for their oral test; the choice of good topics and elaborate language with accurate grammar, they produced highly frequent erroneous substitutions. Those systematic errors of substitution and omission reflect the learners' little knowledge of the TL grammar basic norms even if the time taken for preparation and the choice of topics are generously given to the learners. With this level such as it is, enough awareness of the TL grammar norms is very unlikely. On the other hand, the dominance of systematic omission errors in the dialogue seems to depend to a large extent on the L1 norms. For example, many free morphemes in English are treated as bound morphemes the way they are in the learner's mother tongue. Few examples of those bound morphemes in Arabic are subject pronoun + verb; preposition + object pronoun; article + noun; article + adjective, etc.

In the same vein, even the third person singular bound morpheme in English "-s", which has no counterpart morpheme of the same function in Arabic, is considered as plural "-s" of the plural and overgeneralised as such because the plural "-s" is easily acquired and identified first as its pluralisation function can be clearly instilled in the learner's mind and second it has no counterpart in L1, where pluralisation is rather derivational. The bound morpheme "-s" is overgeneralised most of the time as a plural morpheme although it can very well be first person singular or a possessive 's', which is slightly different in structure. Such a grammatical uncertainty is translated in summarizing those three grammar rules into one; pluralisation. That behavior is due to the lack of practice, and the lack of practice leads to demotivation and ends in instrumentalism in learning a foreign language. In this regard, James (1998) concluded that the lack of grammatical accuracy could be attributable to the restricted chances to produce output.

In the dialogue, the omission error category procedure dominates all other erroneous categories, and that goes hand in hand with a steep rise in the number of errors and the sharp decrease in the quality and quantity of the oral output. The linguistic output produced, especially in the dialogue, reflects grammar errors of all kinds, morphological and lexical, indicating that the type of language knowledge is still explicit despite the long years of exposure.

In sum, the sharp difference in language production between the two modes of speech together with the seriousness of the committed error categories raises a big question about the true quantity of L2 in the learner's interlanguage as well as the role of the L1 grammar norms in producing L2.

\subsubsection{Types of Errors}

Regardless of the density of each type, the two modes of speech subsume the same types of errors. 
The type of L2 grammar error is so important that it reflects the way the learner acquires language, potential role of the mother tongue in producing the L2, and the type of language knowledge gained through practice. There are four major error types detected in the oral output of the subjects under study: overgeneralization, ignorance of rule restrictions, incomplete applications of rules, and false concepts hypothesized (Richards 1971).

In the monologue, the error types are ranked as follows:

1) 25 types of erroneous substitutions;
2) 23 types of erroneous omissions;

3) 11 erroneous additions;

4) 6 erroneous permutations;

Obviously, substitution as well as omission errors are predominant just like wrong additions and permutations; less used and not very different in number.

The big number of all errors types together is 65 , and that is a clear evidence of the great deal of inaccuracy in the language produced in the monologue despite the fact that it was prepared 10 days in advance.

Table 4. The Types of Errors Made by the 50 Subjects Both in the Monologue and Dialogue.

\begin{tabular}{llc}
\hline & ELCS & ELCA \\
\hline MONOLOGUE & & \\
\hline Mean number of erroneous omission types & 25 & 19 \\
Mean number of erroneous Substitution types & 26 & 23 \\
Mean number of erroneous Addition types & 14 & 7 \\
Mean number of erroneous Permutation types & 7 & 5 \\
DIALOGUE & 16 & 11 \\
Mean number of erroneous omission types & 28 & 16 \\
Mean number of erroneous Substitution types & 13 & 14 \\
Mean number of erroneous Addition types & 4 & 6 \\
Mean number of erroneous Permutation types & 4 & 14 \\
\hline
\end{tabular}

The same hierarchy of error types of the monologue is recorded in the dialogue; substitution as the most commonly adopted with 28 times while the omission procedure comes second with adopted 22 times, and the addition is the third with 14 times. They all make up 68 types of errors 3 times more than the types made in the monologue given the number of words produced. Surprisingly, with the few words produced in the dialogue, the number of errors types in all procedures has grown far more than they were in the monologue. In other words, errors of different types thrived in the dialogue, reflecting the extremely poor and highly inaccurate language produced in the dialogue.

\subsubsection{Error Frequency}

In the monologue, the types of errors recorded are highly uneven; some types are very common while others are common, and yet others are less common as indicated in the chart below. In this respect, it is significant to point out to the fact that the ranking of the erroneous categories measured in the chart above is a variable different from the extent to which single types of error are common regardless of the category they belong to. In a word, the commonality of error types is not consistent with the commonality of erroneous categories.

Although the most dominant error category is the substitution, the incomparably most common error type recorded is the omission of article with a mean average of 3.3 errors i.e. bobulation 4 million beoble $\mathrm{K}$. H. R1. That is very expected of the learners whose proficiency level in the target language is low and whose interlanguage is still fully based on the grammar system of their mother tongue. Furthermore, the omission of article is a predicted error as the definite article in Arabic (al-) is bound morpheme i.e. (Altaks haar alyawm $=$ the weather is hot today) and the indefinite article is implicit in Arabic, the learners' mother tongue i.e. (London madeenatun kabeera = London (is) (a) big city). The omission process is due to the fact that indefiniteness in Arabic is marked by the absence of the definite article (Schulz, 2004). In the same line, Elgibali (2005:36) compared the article status in both languages, "In English, the indefinite article is used with the countable noun in the singular form whereas in Arabic there is no indefinite article". This grammar aspect was reinforced in the finding of Alhaysony's (2012) analysis on errors committed by Saudi female EFL learners in their use of articles in their written samples. By and large, L1 interference negatively affected the process of foreign language acquisition of the articles.

The second most common error made in the monologue is the erroneous substitution of countable and uncountable nouns. Such error is not developmental as it abides by a system already established in the interlanguage of the learner i.e. Fast food are expensive TH. GH. N1. Fast food in Arabic is a plural noun. So, Arab learners of English tend to pluralise uncountable nouns as it suits their L1 system. Countability of nouns is not homogeneous between the two languages L1 and L2; many uncountable nouns in English are countable in Arabic i.e. (population, information, fast food). In other words, as they intersect, interlingual factors affect learners' second language perception.

The third most common error in the monologue is the omission of copula with a mean average of 1.7 errors. i.e. $M y$ number ID 0907471" A. F. R1. That is another major systematic error that is clearly L1 negative transfer-based. Back to Arabic, the learners' mother tongue, the copula is implicit. In the same line, (Keshavarz (2006) made it clear that there is no explicit copula as an independent morpheme in Arabic. For that reason, Arab EFL learners have to struggle to distinguish between the grammar norms of their L1 and the TL being studied. Such an elliptical syntactic element in Arabic is negatively transferred to English, 
causing a syntactic gap. In the same respect, Butler-Tanaka (2000) were more specific about that when they claimed that the omission of the copula is more frequent in the present tense than in other tenses. Just like Arabic (Abu-Chacra 2007) who said that Arabic does not have the copula in the present tense.

The three other most common errors are the following. First, the misuse of singular instead of plural forms is the fourth most common error with a mean average of 1.4 i.e. and then continue the (0.7") two packet (1.7") in a day S. M. U2. This particular error seems different in nature from the others. The deficit in providing the plural suffix "-s" to the word "packet" can be interpreted on more than one basis. First, the grammar system of the TL is not well-applied where the learner is still not aware that the regular plural forms in English need the suffix "-s" in a three morphological forms" "-s", "-es", and "-ies". In this case, the error is developmental although it displays a basic gap in the TL knowledge on the part of the learner who shows a low level of L2 competence. It can also be interpreted as an inference based on L1 norms where the number and the noun i.e. "two + packets" are not two free morphemes in Arabic.

They are rather two morphemes bound together in a single word. So, once the learner, with a rare exposure to L2, finds them as two free morphemes, they resort to apply the rule of L1 related to the number; dual numbers in Arabic are bound morphemes making up one compound morpheme (Waladain $=$ two boys). In numbers, from 3 till 10, the noun is pluralized and behaves as a free morpheme i.e. (nine boys) whereas numbers from 11 and above, the noun takes a singular form and also behaves as a free morpheme (ih'daachar walad = eleven boys) as the number is enough to convey pluralisation. (i.e. forty man) although the number is not above 10. Unlike in English, there is no irregular plural in Arabic. So, with a lack of competence in English, the errors like three mans are well-expected.

Tense is the fifth most common type of error with a mean average of 1.34 i.e. It starts $\{f e(0.2$ ") $\}$ from (0.6") seventeenth century until now Y. H. A4. The verb was not conjugated into the present perfect although the adverb of time requires that. Tense wise, there is a big difference in conjugation rules between Arabic and English. There are only two tenses in Arabic; the perfect (the past) and the imperfect (the simple present and simple future). However, there are 9 tenses in English; the perfect, the prefect progressive, and the simple that go with the past, the present, and the future. This goes hand in hand with Abu-Chacra's (2007) conclusion that most Arab EFL students have difficulties in the use of English verbs due to the absence of verb conjugation in Arabic. The perfect type of tense is implicit in Arabic. Morphologically as well, the perfect tense in English requires a helping verb "had" for the past, "have or has" in the present, and "will have" for the future. That grammar rule does not have an equivalent in Arabic. Moreover, the helping verb that does that job is not available as a grammar entity in Arabic. In his study, Abi Samra (2003) found that tense errors are very common among Arab students as there is no time sequence in their language.

The sixth most common error is the subject-verb agreement with an average of 1.32 errors i.e. My father tell me that A. O. U2. This type of systematic error raises a major issue about the type of English instilled in the learner's repertoire. First of all, the third person suffix "-s" is very confusing given the rare exposure to the TL as a foreign language. The suffix "-s" is mostly acquired and digested as a signal of the regular plural form suffix that can only be added to nouns but not to verbs as the students is more familiar with it in that function that was learnt first at the basic level and kept unpractised. That is reinforced by the fact that there is no suffix in the learner's mother tongue that has one form but plays more than one function. Put differently, the pluralisation function of that suffix which is first learnt is the one that will remain the basic norm that the learner seems to abide by, and it is even more potentially digestive in the learner's mind as it has a clear function in the learner's L1, pluralisation. On the opposite, there is no suffix in the learner's L1 that plays the function of a third person singular in the present simple and that is applied to singular subjects as he, she, it in English. However, it is challenging for the learner whose exposure to the TL is rare to accept a second very different function of the same suffix (possessive 's), let a lone a third (third person "-s"). The suffix "-s" declares the regular noun plural but hard to accept it added to a verb in the present simple to declare that the subject is singular. That is very confusing unless abundant exposure and practice makes the difference.

The second function opposes the first. How it declares the plural form when added to a noun and singular when added to a verb in the present simple. What makes the suffix more confusing is the apostrophe 's added to a noun to signal possession. Indeed, many students cannot clearly distinguish between the suffix "-s" and apostrophe "s" due to their similar forms, varied functions, lack of equivalents in the mother tongue, and lack of practice. As for the helping verb used in the present continuous, the singular form "is" is the commonly used one to the extent that it is overgeneralised to include both the singular and the plural (as in Many people in Abha is working H. N. U2) and the present and the past tense (as in He is happy more at that time Gh. H. R1). In other words, the majority of the learners tend to use the singular helping verb "is" more often with both the singular and plural subjects and in both the present and the past continuous tenses. The plural form of the helping verb "are" is kept undigested by a large number of learners in this academic context. A possible interpretation of such a grammatical behaviour is the way conjugations are derived in Arabic; all verb derivations occur partially in Arabic i.e. (yadhhabu (goes), dhahaba (went). Even more, the conjugation of irregular verbs produces completely new forms. So, the subject-verb agreement is most of the time plural subject used with the singular helping verb "is" not the other way round.

The seventh and eight most common errors are related to the same function word - preposition. There is a mean 
average of 1.06 wrong prepositions and 0.96 erroneous omissions of preposition. The grammar element is the same yet the types of errors are two: substitution and omission. The learner either carries out a wrong substitution of prepositions i.e. and then continue two packet in a day $\mathrm{S}$. M. $\mathrm{U} 2$ or omits it all together where they get the money? Y. H. U2. In Arabic, there are 21 prepositions (mawdoo3.com), however, in English, there are about 150 prepositions (Koffi 2010). Also, one preposition in Arabic can have three equivalents in English i.e. the preposition of time ( $\mathrm{fi}=$ in, on; at). So, a major part of this dual errors of preposition is morphological and the no one-to-one relationships of prepositions across the two languages, L1 and L1; some prepositions have equivalent in the other language while others do not.

In this case, the EFL learner may not be aware of grammar rule restrictions given the polysemous nature of the English prepositions that account for those dual errors (Koffi (2010, p. 299). Furthermore, most prepositions in Arabic are free morphemes if they are followed by nouns (min Ahmad = from Ahmad) and bound morphemes they are followed by pronouns $($ minho $=$ from him). However, in both cases, they are always free morphemes in English. Back in the literature, Scott and Tucker (1974) study of preposition found that errors ranked second but in (Mukattash's (1981) they ranked fourth among general grammatical errors. Those two ranks showed the grammatical challenge faced by the Arab EFL learner in acquiring and producing English prepositions, especially at the beginning of the FL learning process. To be more specific, Abu Chacra (2007) claims that simple prepositions were incorrectly used in a high frequency by Arab learners of English due to the transfer of Arabic prepositional knowledge to English.

In sum, the finding in the present study echoed Abi Samra's (2003) assertion that interference from learners' mother tongue was the main cause of errors.

Table 5. The Most Common Error Types Reported both in the Monologue and Dialogue of the Fifty Subjects.

\begin{tabular}{ll}
\hline Monologue & Dialogue \\
\hline The most common error types & \\
\hline 3.3 Omission of article & 1.2 omission of copula \\
1.7 Count vs. uncountable nouns & 1.18 omission of article \\
1.64 Omission of copula & 1.06 omission of subject \\
1.4 Plural vs. singular (regular plural) & 0.74 substitution of tense \\
1.34 Tense & 0.64 omission of preposition \\
1.32 SV & 0.56 addition of article \\
1.06 Wrong Preposition & 0.56 substitution of plural with singular \\
0.96 Omission of a preposition & 0.52 omission of conjunction \\
\hline
\end{tabular}

The dialogue is more expressive of the learner's L2 knowledge and interlanguage make-up as it is online language planning, coding, formulation, and production. It is so spontaneous that the speaker does not have much time to rethink, edit, or elaborate the language to be produced. As such, the online task in the oral presentation under study is characterized by four important facts: the grammar errors were obviously more frequent in the dialogue than in the monologue given the number of words produced whereas the overwhelming category of errors is the omission with $71.21 \%$ of all errors. The omission category is an explicit break of the L2 norms as it drops whole structural entities; lexical or morphological grammar elements. The big density of errors is accompanied with poor quality of language; no sentences or clauses produced. Furthermore, the conscious explicit knowledge does not help the speakers to be spontaneous and with high automaticity of processing in that it takes care of the rules of grammar at the expanse of language elaborateness. In spite of that, a high density of errors was recorded. That implies that the EFL learners under study are not yet aware of the TL grammatical norms, nor have they developed some implicit language knowledge; their conversations lack much of smooth flow of words and elaborate language.

\subsection{Discussion}

As the human brain is naturally behaves according to L1 linguistic patterns, errors while learning a second language as that is something natural in the process of L1 and L2 interaction (Tahaineh, Y. (2010). So, errors represent a clear systematic difference between the two languages. However, what is important in those errors is that they reflect lack of awareness of L2 grammatical system (Ellis, 2003). The language performance in the monologue showed a great deal of deviance from the TL grammatical norms albeit it is a closed task, a major part of the oral presentation, and it was prepared in advance. Even more, the oral presentation was a formal academic test where the speaker is in a competition for the best of grades, yet the language produced is highly inaccurate and strongly influenced by L1 knowledge (James 1998).

In the dialogue, the flow the language produced is not smooth and is clearly poor in quantity and quality. The very few words produced were too sporadic to build up the most basic syntactic units. Similarly, that oral output was full of systematic errors. In this respect, the lack of automaticity indicates that the type of language knowledge is not implicit (Ellis 2005), and that reflects the too much attention given to form and resulted in a high level of inaccuracy the in very few words produced. It is claimed that the L1 grammar transfer operates differently at different stages of the TL learning (Behjat and Sadighi 2010), but that does not seem to apply in the context being studied as the L2 transfer is still in its basic level in spite of the seven years of exposure.

The identification of errors types and categories reveal the 
amount of inadequacies in the learners' interlanguage (Ellis, 2005) and the influence of L1 in L2 production (Cortes, 2006). The category of the error gives an insight into the way the learner thinks of and considers that grammar element. The two major error categories in the monologue are the substitution and omission whereas in the dialogue the omission category comes first and followed by the substitution. The alternation of the two error categories depends very much on the dimensions of each mode of speech. For example, the monologue is a pre-planned closed task and prepared in advance. So, preparation, practice, and editing help raise awareness of the requirements of the L2 grammar norms such as articles, prepositions, countable nouns, etc. As a result, the substitution error category comes first.

A more severe error category, the omission, comes second and very closely to the first category. It reveals serious unawareness and strict breach in the L2 grammar norms in both the monologue and dialogue. Such an error category is more frequent in the dialogue as it is an online mode of speech characterized by more time constraint, spontaneity, and open for discussion and flour winning. As the two language systems are operated in L2 production (Ellis, 2005), the more dependent the speaker is on L1, the more L1 norms dictates which error category prevails. In other words, the more the two language are different, the more interlingual the grammar errors committed are ranging between forms of overproduction, under production, and miscomprehension (Odlin 1989).

As the types of errors are both local and global, they have a marked effect on comprehension and communication (Ellis, 2005). They are both morphological and syntactic and related to meaning and function words. Although the error types are the same in the two modes of speech, error density is markedly unequal where far more errors occur in the dialogue than in the monologue. Likewise, the learners solely depend on the knowledge of the L1 (Ellis \& Barkhuizen, 2005) syntactically and morphologically to deliver their oral messages in that the omitted lexical and morphological elements depend very much on L1 forms (Ellis, 1994).

The strong influence of Arabic marked the systematic error categories and types. That is, all the errors made are cases of overgeneralisations of Arabic language system norms, and that is strongly exerted on the acquisition of L2 (Ellis 2003). Such an aspect echoes Nunan's (2001:89) statement that "Where the first and second language rules are not the same, errors are likely to occur as a result of interference between the two languages." Given that, the application of L1 norms prevents any potential TL mastery. In the Proactive Inhibition PI terms, the effect of prior learning inhibits new learning (Ellis, 2006:174). In this respect, it is significant to point out that widely shaken awareness of the L2 lexical and morphological grammar elements is not only due to the distinct differences morphological systems of the two language, L1 and L2, but also by dint of lack of the learners' L1 grammatical competence. The long period of exposure to the TL, if even there is a lack of exposure and practice, the repetition of the relatively the same grammatical entities over the years may very well drive the learner to be conscious of those entities; subject, object, verb, adverb, preposition, etc. when those entities are not acquired in L1 and stored in the L2 learner's language repertoire, the learning of L2 will be more than challenging as it starts from scratch. Normally, L1 transfer is expected at the preliminary stages of L2 learning (Chen 1999) yet the L1 transfer sustainability prevents the learner from improving learning L2 and from transferring L1 from global to local towards putting it aside altogether. Moreover, it directly affects any speaker's potential mastery of L2. In sum, the interlanguage of the learners under study is based on L1 linguistic system (Selinker 1972) more than being a bi-system language repertoire of two separate norms.

The great error density, especially in the dialogue, implies at least two things: the learner is unconscious of the L1 interference and that the L2 norms acquisition has not taken place given the long years of exposure. Second language learning is an edifying process of the TL knowledge. In each step upward in that process, the types and categories of errors become more and more developmental, local, and less affective of the meaning of the message communicated. Proper language acquisition entails the development of L2 implicit knowledge (Ellis, 2005). In this case, the scarce TL knowledge has grown flat.

The flatness implies lack of unceasing dynamism caused by creative attempts to meet the learning needs. In one of its basic phases, teaching proceeds with testing whether the learner has acquired the forms taught to him or her. The procedure of testing takes different designs and patterns i.e. practising the TL forms of grammar both orally and in written forms through activities devoted to 1) testing the learner's understanding and to 2) for usage and familiarization with the new grammatical norms. That is a proper quest for accuracy. In fact, language communicative competence is built on grammar accuracy and competence (Canale and Swain 1980). Similarly, morphological and syntactic knowledge is considered as among the best measures of language proficiency (Ellis 2005).

A major step towards a proper acquisition of a second language is to teach the grammar of the mother tongue in detail, and to make sure the learner recognises all grammatical elements in L1 in form and in meaning to be able to identify their counterparts in the TL. When the second language learner is fully aware of the grammatical norms in L1 (i.e. subjects, verbs, articles, prepositions, nouns, etc.), their morphological structure, where they are properly placed, and how they together build a sentence, every TL grammatical element would make sense in form and function. Moreover, the learner would wonder before they acquire L2 norms, compare them to the L1 norms, and how they construct syntactic unit that deliver a message, and how different they are from the L1. A conscious comparison of the two norms would help for the acquisition of the L2 norms appropriately. It is the recognition of norms differences that creates motivation for learning and more practice, leading the L2 grammar knowledge to grow implicit. 
It is clear that the learner-centred approach of teaching is the magic key to those everlasting basic lexical and morphological grammar inadequacies. Tailor-made activities could address the learner needs in details, allow them to practice (Javid 2011) the new structures in context, and make them possess inductive reasoning in acquiring rules of grammar. Similarly, creative tasks where the relationship between form and function is transparent strengthen the learners' grammatical competence Nunan (2001:193). Abundant practice directed to enhance the learners' TL grammar acquisition increases their self-confidence, reinforce their impulse for argument, and make them more attentive.

Those activities need to be within a context-sensitive pedagogic framework (Kumaravadivelu 2006) to attract the learner more towards the aimed goals assigned. When the learner assumes more roles in the learning process, a new partnership would be established, and the teaching objectives would be easily met at the time allocated for that. Once the teacher is aware of the learners' needs, personal differences, motivating topics, and preferences, the learner will be more motivated, more productive, more cooperative, and more competent. At that time the teacher will assume more a single role; he/she can be a facilitator, a monitor, an advisor, a guide, etc.

However, as when English teachers spend the majority of the lesson talking and rarely allow students a chance to speak or ask questions Fareh (2010), the learners potential dynamism and interaction would be at risk. In fact, Alkubaidi (2014) indicated that classes are usually quiet as students take a passive role in the learning process. That is an expected outcome when language learning does not address the learners' needs so that the learner is likely to assume a clear role. Similarly, many tailor-made and well-designed activities encourage learning language structure inductively and artistically. For example, teaching tenses could be through activities like summarizing a story, writing a diary, describing a picture, etc. On the opposite, Rajab (2013) admitted that in English classes, most students apply memorization as the main approach for learning. They memorize certain samples of paragraphs, grammar rules, or vocabulary items without understanding their meanings or their syntactic or morphological structure. The main objective behind doing that is to guarantee a pass grade.

\section{Conclusion and Recommendations}

The FL learner's linguistic competence is built in layers of academic commitments to learner-centredness pedagogy. Less awareness of the learner's needs, on the other hand, would result in limited L2 knowledge. It is, therefore, recommended that the language teaching task - teaching materials, textbook contents, and TL practice - make of the learner's L2 knowledge a sole aim. More communication with the learner through discussion, surveys, feedback, and collaboration helps for proper L2 acquisition.

\section{References}

[1] AbiSamra, N. (2003). An analysis of errors in Arabic speakers' English writing. In Mourtaga, K. (Ed.), Investigating writing problems among Palestinian students studying English as a foreign language. Unpublished doctoral dissertation.

[2] Abu-Chacra, F. (2007). Arabic, an Essential Grammar. New York, Routledge.

[3] Adams, Marianne L. (1980). Five Co-occurring Factors in Speaking Proficiency. In James R. Firth (Ed.), Measuring spoken language proficiency (pp. 1-6). Washington, DC: Georgetown University Press.

[4] Alhaysoni, M. (2012). An Analysis of Article Errors among Saudi female EFL students: A case study. Asian Social Science, 8(12).

[5] Alkubaidi, M. A. (2014). The Relationship between Saudi English Major University Students' Writing Performance and Their Learning Style and Strategy Use. English Language Teaching, 7(4), 83-95.

http://www.ccsenet.org/journal/index.php/elt/article/view/349 33/19895 27/08/2017.

[6] Behjat, F. \& Sadighi, F. (2010). Iranian English Major Students' L2 Grammar Development: Linguistic Threshold hypothesis. The Electronic Journal for English as a Second Language, 13(4), A-6. Retrieved April 22, 2017 from http://teslej.org/pdf/ej52/a6.pdf.

[7] Canale, M. \& Swain, M. 1980. Theoretical Bases of Communicative Approaches to Second Language Teaching and Testing. Applied Linguistics, 1 (1), p. 1-47.

[8] Butler-Tanaka, P. (2000). Fossilization: A Chronic Conditioner is Consciousness-raising the Cure? Unpublished MA Thesis, University of Birmingham, Birmingham.

[9] Chen, Y. (1999). A Portfolio Approach to EFL University Writing Instruction. Proceedings of the sixteenth conference on English teaching and learning in the Republic of China. Taipei: The Crane Publishing Co., Ltd.

[10] Corder, S. P. (1981). Error Analysis and Interlanguage. Oxford: Oxford University Press

[11] Corder, S. P. (1973). Introducing Applied Linguistics. Harmonds worth: penguin.

[12] Cortes, V. (2006). Teaching Lexical Bundles in the Disciplines: An example from a writing intensive history class. Linguistics and Education, 17, 391-406.

[13] Council of Europe, 2001:112-113 www.coe.int/lang $02 / 09 / 2017$

[14] Cummins, James. (1979). Linguistic Interdependence and the Educational Development of Bilingual Children. Review of Educational Research, 49, 222-251.

[15] Cummins, James. (1976). The Influence of Bilingualism on Cognitive Growth: A Synthesis of Research Findings and Explanatory Hypotheses. Working Papers on Bilingualism, 9, $1-43$.

[16] Eisenstein-Ebsworth, M. and Schweers, C. W. (1997). What Researchers Say and Practitioners Do: Perspectives on Conscious Grammar Instruction in the ESL Classroom. Applied Language Learning 8, 237-260. 
[17] Elgibali, A. (2005). Investigating Arabic: Current Parameters in Analysis and Learning. Studies in Semitic Languages and Linguistics Series. Brill Academic Publishers, Boston, MA.

[18] Ellis, N. C. (2006). Selective Attention and Transfer Phenomena in L2 Acquisition: Contingency, Cue Competition, Salience, Interference, Overshadowing, Blocking, and Perceptual Learning. Applied Linguistics, 27, 164-194.

[19] Ellis, R., \& Barkhuizen, G. (2005). Analysing Accuracy, Complexity, and Fluency Analysing Learner Language (pp.139-164): Oxford University Press. Ellis, R. (1997). Second Language Acquisition, Oxford University Press, Oxford.

[20] Ellis, R. (2005). Measuring Implicit and Explicit Knowledge of a Second Language: A Psychometric Study. Studies in Second Language Acquisition, 27. 141-172.

[21] Ellis, R. (2003). Task-based Language Learning and Teaching. Oxford, England: Oxford University Press.

[22] Ellis, Rod (1994). The Study of Second Language Acquisition. Oxford University Press.

[23] Ellis, R. (1990). Instructed Second Language Acquisition. Oxford: Basil Blackwell.

[24] El-Sayed, A. M. (1982) An Investigation into the Syntactic Errors of Saudi Freshmen's English Compositions. Unpublished Ph.D. Indiana University of Pennsylvania.

[25] Encyclopaedia Britannica https://www.britannica.com/topic/grammar retrieved on 17 April, 2017

[26] Fareh, S. (2010). Challenges of Teaching English in the Arab World: Why Can't EFL Programs deliver as expected? Procedia Social \& Behavioral Sciences.2, 3600-3604.

[27] Gass, S. (2003). Input and Interaction. In C. Doughty \& M. Long (Eds.), Handbook of second language acquisition (pp. 224-255). Oxford: Blackwell.

[28] Guará-Tavares, M. (2008). Pre-task Planning, Working Memory Capacity and L2 Speech Performance. (Unpublished doctoral dissertation). Universidade Federal de Santa Catarina, Florianópolis, Brazil.

[29] Hachem, N. (1996). English Syntactic Errors by Arabic Speaking Learners Reviewed. Eric. Doc 423660 Full Text.

[30] Hill, J. and Flynn, K. (2006) Classroom Instruction that Works with English Language Learners. Virginia: ASCD.

[31] Homburg, T. J. (1984). Holistic Evaluation of ESL Compositions: Can It Be Validated Objectively? TESOL Quarterly: 18, 87-107.

[32] Ishikawa, S. (1995). Objective Measurement of LowProficiency EFL Narrative Writing. Journal of Second Language Writing, 4(1), 51-59.

[33] James, C. (1998). Errors in Language Learning and Use. London: Longman.

[34] Javid, C. Z. (2011). An Analysis of Saudi Medical Undergraduates' Perceptions of English Language Needs: a Comparative Study. Madina Manawarra: Paper presented at the international conference "Inside the Saudi Preparatory Year English Program: The Future and Beyond", 12-13 April
2011.

[35] Keshavarz, M. H. (2006). Error Analysis: A Practical Course for English Students and Teachers. SAMT, Tehran.

[36] Koffi, E. (2010). Applied English syntax: Foundations for word, phrase, and sentence analysis. Dubuque, Iowa: Kendall Hunt Publishing Company. Print.

[37] Krashen, S., \& Terrell, T. D. (1983). The Natural Approach: Language Acquisition in the Classroom. Oxford: Pergamon.

[38] Kuiken, Folkert and Ineke Vedder (2007). Cognitive Task Complexity and Linguistic Performance in French L2 Writing. In Inves- tigating Tasks in Formal Language Learning, Maria del Pilar García Mayo (ed.), 117-135. Clevedon: Multilingual Matters.

[39] Kumaravadivelu, B. (2006). TESOL Methods: Changing Tracks, Challenging Trends. TESOL Quarterly, 40, 59-81.

[40] Lambert, C. P., \& Engler, S. (2007). Information Distribution and Goal Orientation in Second Language Task Design. In M. P. Garcia Mayo (Ed.). Investigating Tasks in Formal Language Learning (pp.27-43). Clevedon: Multilingual Matters.

[41] Li, W. (2012). An Eclectic Method of College English Teaching. Journal of Language Teaching and Research, 3 (1): 166-171.

[42] Mangubhai, F. (2006). What Do We Know about Learning and Teaching Second Languages: Implications for teaching. Asian EFL Journal, 8(3), 46-68. (September 2006 Conference Proceedings: Task-based Learning in the Asian Context)

[43] Mukattash, L. (1981). Wh-Questions in English: A Problem for Arab Students. International Review of Applied Linguistics in Language Teaching, 19 (4), 317- 332.

[44] Nassaji, H. \& Fotos, S. (2011). Teaching Grammar in Second Language Classrooms: Integrating form-Focused Instruction in Communicative Context. New York: Routledge.

[45] Nation, I. S. P., \& Newton, J. (2009). Teaching ESL/EFL Listening and Speaking. ESL \& Applied Linguistics Professional Series. Routledge Taylor \& Francis Group.

[46] Nunan, D. (2001). Second Language Acquisition. Carter, R. \& Nunan, D., (eds.). The Cambridge Guide to Teaching English to Speakers of Other Languages [C], pp 87- 92. Cambridge: Cambridge University Press.

[47] Odlin, T. (1989). Language Transfer. Cambridge: Cambridge University Press.

[48] Ortega, L. (2003). Syntactic Complexity Measures and their Relationship to L2 Proficiency: A Research Synthesis of College-Level L2 Writing. Applied Linguistics, 4(24), 492518 .

[49] Oxforddictionaries (http://www.oxfordlearnersdictionaries.com) (17 April 2017).

[50] Rajab, H. (2013). Developing Speaking and Writing Skills of L1 Arabic EFL Learners through Teaching of IPA Phonetic Codes. Theory and Practice in Language Studies, 3, 653-659. http://dx.doi.org/10.4304/tpls.3.4.653-659

[51] Richards, J. C. (1971). Error Analysis and Second Language Strategies. Language Sciences, 71 (17), 12-22. 
[52] Ruiz-Funes, M. (1999). Task Representation in Foreign Language Reading-to-Write. Foreign Language Annals, 34(3), 226-234

[53] Salomone, A. (1992). Student-teacher Interactions in Selected French Immersion Classrooms. In E. B. Bernhardt (Ed.) Life in language immersion classrooms (pp. 97-109). Clevedon, England: Multilingual Matters Ltd.

[54] Selinker, L. (1992). Rediscovering Interlanguage. London: Longman.

[55] Scott, M. \& Tucker, G. (1974). Error Analysis and Englishlanguage Strategies of Arab Students. Language Learning, 24, 69-97.

[56] Skehan, P., \& Foster. P. (1999). The Influence of Task Structure and Processing

[57] Conditions on Narrative Retelling. Language Learning, 49 (1), 93-120.

[58] Schulz, E. (2004). A Student Grammar of Modern Standard Arabic. Cambridge: Cambridge University Press.
[59] Tahaineh, Y. (2010). Arab EFL University Students' Errors in the Use of Prepositions. MJAL2:1JANUARY2010. ISSN 0974-8741. Retrieved on 15, Sept, 2010 from: http://www.ibe.unesco.org/fileadmin/user_upload/archive/Cou riers/WDE/2006/ARAB STATES/Saudi Arabia/Saudi_Arabia.pdf. Retrieved January 3, 2016.

[60] Terrell, T. D. 1991. The Role of Grammar Instruction in a Communicative Approach. The Modern Language Journal 75: $52-63$.

[61] VanPatten, B. (1990). Attending to Form and Content in the Input. Studies in Second Language Acquisition, 12, 287-301.

[62] Widdowson, H. (1990). Aspects of Language Teaching. Oxford: Oxford University Press.

[63] Wilkins, D. A. (1976). Notional Syllabuses. Oxford, Oxford University Press.

[64] Wolfe-Quintero K., Inagaki S. and Kim. H.-Y. (1998). Second Language Development in Writing: Measures of Fluency, Accuracy, and Complexity. Honolulu: University of Hawaii Press. 